\title{
O Debate Acerca do Ensino de Sociologia no SeCundário, Entre as DéCADAS de 1930 E 1950. Ciência e Modernidade no Pensamento EdUCACIONAL BrasileIRO ${ }^{1}$
}

\author{
Flávio Marcos Silva Sarandy²
}

\begin{abstract}
Resumo
O discurso educacional das décadas de 1930 a 1950 considerou a ciência como o caminho coerente de compreensão da realidade nacional e a educação, a principal arena de intervenção nas relações sociais, portanto, uma educação orientada pela ciência em suas linhas mestras, em termos de política educacional e, internamente, em termos de didática e currículo, e tendo como principal conteúdo o conhecimento produzido pela própria ciência, com vistas à democracia e ao ingresso do Brasil na modernidade capitalista. 0 artigo discute a relevância do ensino de sociologia no pensamento educacional brasileiro a partir da articulação entre determinadas variáveis como "democracia", "ciência" e "modernidade", e sugere que em textos de Florestan Fernandes, Costa Pinto e Antônio Cândido, por exemplo, há uma associação entre certa concepção de democracia, uma perspectiva que se pretende modernizante das relações sociais no Brasil e a proeminência da educação como projeto estratégico de modernização e desenvolvimento democrático justamente devido à formação de "capacidades" necessárias aos cidadãos brasileiros, em que o ensino de sociologia na educação básica ocupou lugar de destaque para o projeto, num contexto efervescente de ruptura com um passado tido por representante do nosso atraso.

Palavras-Chave: Ensino de Sociologia. Política educacional.
\end{abstract}

\section{Abstract}

The educational speech of decades of 19301950 considered the science as the way of coherent understanding of the national reality and education, the main arena of

\footnotetext{
${ }^{1} 0$ artigo reúne resultados alcançados em minha dissertação de mestrado (2004) e, principalmente, resultados de pesquisa em andamento.

${ }^{2}$ Professor de ciências sociais em Vitória e mestre em sociologia pela Universidade Federal do Rio de Janeiro.
} 
intervention in social relations, therefore, an education geared for science in its guiding principles, in terms of educational policy and, internally, in terms of teaching and curriculum, and with the main content knowledge produced by the science itself, with views on democracy and the entry of Brazil in the capitalist modernity. The article discusses the importance of the teaching of sociology at the Brazilian educational thought from the linkage between certain variables such as "democracy", "science" and "modernity", and suggests that in texts of Florestan Fernandes, Costa Pinto and Antonio Cândido, for example, there is an association between a conception of democracy, a prospect that is to be studied social relations in Brazil and the prominence of education as a strategic project of modernization and democratic development rightly due to the formation of "skills" needed to Brazilian citizens, where the teaching of sociology at the high school took place of prominence for the project, in a context of effervescent break with a past taken by representative of our delay.

Key words: Teaching of sociology Educational policy. Educação básica. High school

$\mathrm{N}$ as décadas de 30 a 50 do séc. XX houve um intenso debate sobre educação, realizado por intelectuais brasileiros de projeção, como, entre outros, Emílio Willems, Fernando de Azevedo, Luiz de Aguiar Costa Pinto, Florestan Fernandes, Antônio Cândido e Anísio Teixeira. Digno de nota é o (possível) influxo pragmatista no discurso educacional brasileiro, capitaneado por Anísio Teixeira após sua passagem pelos EUA e a influência direta que sofreu de John Dewey, talvez simplesmente por uma influência vaga, gerada mais pela ubiqüidade das idéias deweyanas do que por uma filiação teórica direta ${ }^{3}$; bem como deve-se ressaltar as preocupações com a democracia no Brasil, na esteira do pensamento pragmático, em que a educação é elevada a estratégia transformadora.

O ideário educacional renovador como apresentado no "Manifesto dos Pioneiros", de 1932, foi reproduzido largamente por Costa Pinto e Florestan Fernandes, em que, democracia, ciência e educação não se dissociariam de um projeto modernizador da sociedade e do Estado brasileiro e no qual a sociologia (o ensino desta) ocuparia lugar privilegiado. Estudos sobre a filosofia educacional de Anísio Teixeira e Fernando de Azevedo (PAGNI, 2000) dão conta das complexas trocas intelectuais ocorridas no período e se oferecem como modelos de análise a serem adotados. Adespeito do campo comum de debates, a educação, em que foram forjados os discursos que serão considerados neste texto, o artigo pretende resgatar aspectos do pensamento social brasileiro pouco considerados até o momento.

Proponho apontar registros, para pesquisa, de um possível influxo pragmatista no pensamento educacional brasileiro (como parte do pensamento social e político

\footnotetext{
${ }^{3}$ Devo a ressalva ao Dr. Marcus Vinícius da Cunha, com o qual tive o privilégio de compartilhar essas reflexões.
} 
brasileiro) a partir da articulação entre determinadas variáveis como "democracia", "ciência" e "modernidade". Isto porque podemos ver claramente (em textos de Florestan Fernandes, Costa Pinto e Antônio Cândido) uma associação entre uma certa concepção de democracia, uma perspectiva que se pretende modernizante das relações sociais no Brasil e a proeminência da educação como projeto estratégico de modernização e desenvolvimento democrático justamente devido à formação de "capacidades" necessárias aos cidadãos brasileiros; ou, em outros termos, o discurso educacional das décadas de 1930 a 1950 considerou a ciência como o caminho coerente de compreensão da realidade nacional e a educação, a principal arena de intervenção nas relações sociais. Portanto, uma educação orientada pela ciência em suas linhas mestras, em termos de política educacional e, internamente, em termos de didática e currículo, e tendo como principal conteúdo o conhecimento produzido pela própria ciência, com vistas à democracia e ao ingresso do Brasil na modernidade capitalista constitui o núcleo do pensamento educacional do período.

Independentemente de enxergarmos nesses discursos a presença do pragmatismo norte-americano, seria interessante verificar como alguns intelectuais brasileiros de fins da primeira metade do século XX relacionaram os termos referidos num projeto ambicioso de modernização social e política, e como a sociologia ocupou lugar de destaque nesse projeto, num contexto efervescente de ruptura com um passado tido por representante do nosso atraso. A questão fundamental, portanto, refere-se a como se articularam os termos mobilizados no discurso educacional brasileiro do período em questão, bem como a carga semântica atribuída aos mesmos, a partir do lugar previsto para a sociologia enquanto disciplina da matriz curricular do ensino secundário.

\section{A SOCIOLOGIA DO SECUNDÁRIO À ACADEMIA: INSULAMENTO, INVISIBILIDADE E ESQUECIMENTO}

A institucionalização das ciências sociais no Brasil não se deu quando de seu ingresso na academia através dos primeiros cursos regulares de formação específica em

ciências sociais, mas pela sua presença no antigo curso normal e no curso secundário, ainda nas primeiras décadas do século XX. E não somente pela sua inclusão no sistema de ensino. Ao contrário, parte importante dessa história se desenrolou no esforço de alguns intelectuais para publicar obras de sistematização do conhecimento sociológico ou traduzir importantes textos de autores estrangeiros. 0 processo de institucionalização das ciências sociais em nosso país encontrou guarida, em sua primeira fase, no ensino secundário antes que na academia (MEUCCI, 2000; GIGLIO, 1999). 
A rigor, não existiam universidades (MEL0, 1999; MEUCCI, 2000). Sabe-se que após a transferência da Coroa Portuguesa para o Brasil , em 1808, foram inauguradas imediatamente a Academia Militar, a Escola Nacional de Belas Artes e duas faculdades de medicina, uma no Rio de Janeiro e outra na Bahia, de onde surgiram algumas obras de filosofia publicadas no Brasil no século XIX. Somente em 1827 é que são criadas as faculdades de direito de Olinda - posteriormente transferida para o Recife - e de São Paulo. Assim compõe-se o nosso sistema de ensino superior até a terceira década do século XX. E ainda assim, tanto a criação da USP, como da Escola Livre de Sociologiae Política ou a "agregação" de cursos na Universidade do Rio de Janeiro, eventos que se deram na primeira metade da década de 1930, podem ser considerados casos isolados e não representaram o que seria 0 início de uma política governamental de fomento à educação superior.

Mesmo com a expansão do ensino superior a partir dos anos 30, é somente após 1964 que o Brasil vai conhecer um processo de "democratização do ensino superior" e de incentivo à pesquisa, além de uma política voltada à criação de universidades e programas de pós-graduação, na linha da modernização industrializante do regime militar (MELO, 1999). No entanto, a produção em ciências sociais já existia desde antes e se a inexistência desses cursos universitários, por um lado, é a condição objetiva que favoreceu a sociologia enquanto disciplina do ensino secundário, por outro, não é condição suficiente para explicar o fenômeno. Pois, se a inexistência de um sistema universitário nos obriga a relativizar a importância atribuída à inserção da disciplina no secundário como algo excepcional, não justifica, todavia, o desinteresse atual pelo que se fez na época, no secundário. 0 sentido da presença da sociologia no secundário à época só se revela quando se compreende seu lugar dentro de um projeto intelectual e político mais amplo, em que educação e modernidade figuram como elementos indissociáveis.

Há algo importante a se ressaltar aqui: foi nas escolas normais e de preparação para o ingresso em cursos superiores que surgiram os primeiros esforços de sistematização do pensamento sociológico em nossa sociedade por meio de livros destinados ao ensino da nova disciplina - seus manuais didáticos - e, ainda, a partir da década de 1930, de artigos que buscavam refletir as experiências de ensino acumuladas. Produção que em muitos aspectos preenchia a lacuna de pesquisas de maior porte sobre a realidade brasileira (MEUCCI, 2000; SARANDY, 2004).

A ciência social conheceu um período de intensa produção intelectual anterior à década de 1930 e mesmo antes de sua institucionalização em programas de pós-graduação, a partir de meados do século XX, já se pode falar de um campo da ciência social, cuja prática, se não estava associada a um sistema acadêmico, era bastante próxima da política de Estado e participante do debate público. Disso decorre ser o processo de 
institucionalização muito mais complexo que somente a inserção da ciência social na academia (MELO, 1999). No entanto, os estudos no campo privilegiaram o ingresso das ciências sociais nas universidades e nos programas de pós-graduação, chegando mesmo a qualificar o período anterior, justamente o das ciências sociais no secundário, de sua "fase pré-científica" (AZEVEDO, 1969).

Cabe uma crítica a esse argumento comum sobre a história da sociologia no Brasil, desenvolvido, entre outros, por Fernando de Azevedo e Florestan Fernandes, e que compreende a disciplina como tendo percorrido três fases principais: uma pré-científica e anterior à institucionalização acadêmica, que se estende da segunda metade do século XIX até $1928^{4}$; uma que corresponde ao período de "introdução do ensino dessa matéria em escolas do país, de 1928 a 1935"; e, outra, pautada por "rigorosos padrões científicos de pesquisa e ampla produção acadêmica", que cobre os anos de 1935 aos dias atuais. Parece-me correto afirmar que devido à projeção desses sociólogos a eles se deve debitar a consolidação dessa imagem distorcida. Mas que não se subestime o grau de consenso que ainda há sobre a matéria atualmente. Essa percepção de uma fase "pré-científica" no pensamento social e político brasileiro que tem caracterizado o período das primeiras décadas do século XX como algo bastante singular, justamente o período dos primeiros escritos sobre a sociologia no ensino secundário, é resultante do distanciamento que a academia tomou da educação básica (MEL0, 1999; SARANDY, 2004).

Mas sabemos que toda periodização é sempre, em algum grau, arbitrária. E, nesse caso em particular, se ela nos revela a importância do ensino da disciplina para aqueles sociólogos do início do século XX $X^{5}$, por outro nos revela também a intenção de elevar-se a sociologia à condição de ciência com reconhecimento social. Na verdade, não apenas se creditava à disciplina a condição de ciência fundamental, na esteira do pensamento comtiano, capacitada para o conhecimento seguro da realidade social e fornecedora de instrumentos de intervenção que contribuíssem para a harmonia e o desenvolvimento da sociedade; mais que isso: a considerar as relações de parte desses intelectuais com 0 pragmatismo de Dewey e a forte influência, nos anos 20 e 30, da Educação Nova no Brasil, capitaneada por Anísio Teixeira, é compreensível que a sociologia seja alçada à condição de "arte de salvar rapidamente o Brasil", nos dizeres de Mário de Andrade. Há um forte componente missionário na produção do período que ainda está por ser investigado.

\footnotetext{
${ }^{4}$ Ano de implantação do primeiro curso de sociologia no ensino normal, no Colégio Pedro II, por Delgado de Carvalho.

5 É significativo o fato de Azevedo (1969) ressaltar e classificar como um período da história da sociologia justamente o de sua inserção nos sistema de ensino secundário, a partir de 1928, por meio de um recorte da história da disciplina sociológica muito peculiar: a despeito da crítica a inexistência dos "rigorosos padrões de pesquisa científica", privilegia os anos em que esta esteve presente no secundário como um período a ser destacado.
} 
Segundo os trabalhos de Villas Bôas (1998), Giglio (1999), Santos (2002) e Rêses (2004), a disciplina sociologia teria sido proposta ainda no Império, em 1881, a partir de um projeto para a re-estruturação do ensino no Brasil, de Benjamin Constant. A proposta foi descartada após a morte de Constant, retirada do currículo pela Reforma Epitácio Pessoa, de 1901, "sem nunca ter sido ofertada" e efetivada (RÊSES, 2004, p. 7), outra vez propostapela Reforma Rocha Vaz, em 1925, e ratificada com a Reforma Francisco Campos, em 1931. Em 1942, no entanto, a Reforma Capanema retira a obrigatoriedade do ensino da sociologia da escola secundária ${ }^{6}$ e entre esse ano e 1960 "assiste-se a um ataque oficial às ciências sociais, que vai sendo inibida, pouco a pouco, no ensino secundário, sobrevivendo apenas no curso superior e na escola normal" (CORREA, 1999). Em nota de rodapé, Meucci (2000, p. 74) sugere que tal retirada

causou um impacto, inicialmente negativo, sobre os cursos de ciências sociais oferecidos pelas universidades e faculdades. Até então dedicadas quase totalmente ao ensino, e com o desenvolvimento ainda débil da pesquisa científica, as ciências sociais brasileiras foram submetidas a uma redefinição dentro do sistema intelectual e da relação entre o desenvolvimento do ensino e da pesquisa científica. 0 impacto da retirada da sociologia dos cursos secundários exigiu novo redirecionamento dos cursos acadêmicos antes voltados particularmente para a preparação de professores mais do que pesquisadores propriamente ditos.

A passagem da sociologia dos cursos normal e secundário para a academia constituiu um processo que em nossa sociedade se deu efetivamente nos dois períodos de regime autoritário que a sociedade brasileira conheceu: primeiro, durante o Estado Novo e, depois, pelas mãos do golpe militar de 64, com a expansão da pós-graduação - o que deixou marcas no modo como compreendemos as ciências sociais e seu lugar na sociedade e que os livros didáticos expressam de modo singular. Sobre o período que interessa

\footnotetext{
${ }^{6}$ A ausência da sociologia nos currículos escolares em nível nacional persistiu desde a Reforma Capanema, que data de 1942, até a década de 1980, quando começou a ser re-inserida de modo intermitente (MEKSENAS, 1995, apud CORREA, 1999) e paulatino em alguns estados brasileiros. Essa discussão também está presente nos trabalhos de Villas Bôas (1998), Giglio (1999), Santos (2002), Rêses (2004), Meucci (2000) e Sarandy (2004), Surpreendente é o desconhecimento ou desprezo desse fato por grande parte dos cientistas sociais, a despeito de sua relevância para investigações acerca de política educacional. 0 efeito do regime autoritário instaurado em 64 sobre o ensino de sociologia no ensino médio (à época, "secundário") se não foi o de retirada da disciplina do currículo, foi o de ter conseguido desarticular o debate acadêmico ocorrido nos anos 30 e 40; durante a ditadura militar o campo das ciências sociais experimentou um insulamento acadêmico, obviamente relacionado às ações do governo golpista, mas também devido ao redirecionamento dos interesses e re-organização no próprio campo, insulamento que provocou o desinteresse pela sociologia como disciplina viável no ensino de segundo grau e lançou ao esquecimento o debate das décadas anteriores. A vitimização da disciplina como mais um alvo da instauração da ditadura militar a partir de 1964 serve bem ao espírito corporativista com que vem sendo tratada e pode ser mais um capítulo do messianismo inerente à ciência social no Brasil.
} 
diretamente a esse artigo, cabe perguntar que impacto a Reforma Capanema provocou, precisamente.

Se o Estado Novo provocou uma estagnação de cerca de oito anos no pensamento político-social brasileiro e afastou a sociologia do secundário, o regime militar consolidou seu insulamento acadêmico e a afastou dos debates públicos. Compreensível diante do grau de importância a que as ciências sociais foram elevadas desde o início do século no imaginário social do país e do grau de autonomia dos intelectuais. Colocar sob controle essa efervescência reformadora deveria passar necessariamente pelo seu afastamento dos centros decisórios e dos espaços de influência intelectual. Entretanto, diferente das explicações que se tem oferecido por matizes ideológicos, o efeito mais desastroso para a ciência social brasileira foi seu insulamento academicista, que pouco a pouco lhe retirou o papel central que ocupara na definição da agenda pública em décadas anteriores.

Na década de 1930 o início do processo da institucionalização strictu sensu se deu via criação de universidades e cursos de graduação. A partir de 1960, a institucionalização ocorreu via criação dos programas de pós-graduação por meio dos quais se podem falar propriamente em linhagens e práticas de pesquisa. Sem dúvida, Melo (1999, p. 174) apresenta que "a expansão da pós-graduação constitui o melhor indicador da institucionalização das ciências sociais no Brasil". É no mínimo curioso 0 fato da instituição dos programas de pós-graduação, no Brasil, ter ocorrido após 1968 em sua maioria. Com exceção de casos isolados, como a concessão dos títulos de mestre e doutor pela USP desde ao menos 1947, os primeiros programas de pós-graduação foram instituídos entre fins da década de 1960 e início de 1970 (MEL0, 1999, p. 210), fato que demonstra um período de concentração na emergência dos programas de pós-graduação. 0 início da institucionalização, no entanto, como vimos, conheceu uma fase anterior, pela sua inserção da disciplina no secundário e pela produção dos seus primeiros manuais e textos de reflexão e é justamente essa produção que nos interessa compreender em seus meandros.

Ocorre que a institucionalização do campo se deu em direção à sua consolidação enquanto prática científica com sua crescente inserção na universidade pública e constante re-arranjos institucionais, além de rupturas e esquecimento. Processo pleno de paradoxos e conflitos por meio do qual foi se constituindo um novo papel e um novo lugar social para a disciplina. Portanto, "tem-se uma trama institucional, cuja articulação é exercida indiscutivelmente pelos centros de pós-graduação” (MEL0, 1999, p. 177), sendo esta o seu ápice de hierarquização. Dessa forma que se pode falar num ensino e numa pesquisa, ou em professores e pesquisadores em ciências sociais, sendo esses os dois pólos pelos quais se pode observar a institucionalização acentuada experimentada pelo campo. 
Tais iniciativas seguiam o projeto de modernização econômica do regime autoritário e deixou marcas profundas nas ciências sociais, produzindo "intelectuais comprometidos com a lógica da carreira e da institucionalização da atividade intelectual [e um] sistema de orientação [que os] manteve [...], por muito tempo, afastado das controvérsias políticas e da vida pública" (MELO, 1999, p. 218). É que, "0 regime autoritário inaugura uma descontinuidade na história da ciência social brasileira, que alcança diversas dimensões. Por força da repressão política desencadeada contra seus opositores, operou uma seleção implícita dos intelectuais" (p. 211); pior que isso foi "0 fato de ter imposto aos cientistas sociais mais jovens - e por esta razão, menos expostos à ação discricionária do regime autoritário - um padrão de formação e de institucionalização desprovido de conexões efetivas com a sociedade e a vida pública, dado o contexto geral de restrições à liberdade" (p. 211).

Melo (1999, p. 212) nesse processo de institucionalização "criou, a partir do final dos anos 60, uma situação, por qualquer critério, inusitada: uma ciência social impedida de estabelecer conexões efetivas com a sociedade e, simultaneamente, isolada da vida universitária”. Portanto, uma nova condição para a prática científica já estava dada com a implantação da pós-graduação, de padrões mais rígidos de pesquisa empírica, com a renovação dos quadros por novas gerações de cientistas acadêmicos e pelo relativo distanciamento das ciências sociais em relação à vida pública. 0 que se pode dizer a respeito desse período de institucionalização das ciências sociais é que sua profissionalização e especialização extremas lhe impuseram uma condição de elevado insulamento, conforme a noção de "insulamento burocrático", nos termos de Edson Nunes (1999). Ora, a lógica do insulamento pressupõe três coisas fundamentais: uma extrema especialização, com acentuada divisão racional do trabalho intelectual; um relativo fechamento em "ilhas burocráticas" de especialistas detentores de informação privilegiada e com um mínimo de influência externa; por fim, um caráter setorial, aplicado à gestão racional e eficiente de um setor específico da vida pública, sem incursões generalizadas no debate dos grandes temas - há mesmo uma indiferença pela agenda pública vista em sua totalidade. A participação ativa por parte de nossos intelectuais, de caráter até mesmo missionário, interessada na modernização da sociedade brasileira, foi substituída pelo desempenho profissional, constituído por um ethos científico.

A despeito do duro golpe sofrido com o regime de 64, a ciência social acadêmica, pouco a pouco, retornou à vida pública na linha de oposição ao regime e de afirmação das liberdades democráticas, cada área de conhecimento (sociologia, antropologia e ciência política) em seu próprio ritmo e condições distintas (MELO, 1999). No entanto, a profissionalização impôs um relativo insulamento de tipo burocrático à prática científica 
e mesmo a oposição democrática ao regime, como esboçada por Melo, se deu do interior da universidade e de modo "bem controlado", em outras palavras, de forma disciplinada pelo fazer científico. Não podemos esquecer que o investimento do regime militar nas humanidades e nas ciências sociais foi muito menor em relação às áreas das ciências "duras" e mais intimamente ligadas à tecnologia. Esse processo de parcos investimentos e profissionalização universitária, inclusive pelo sistema de gestão colegiada e departamental, criou uma competição por recursos e redirecionamento dos interesses da comunidade.

0 insulamento universitário das ciências sociais, portanto, é resultado de um duplo processo: a implementação de políticas profissionalizantes, conforme o projeto modernizante do regime militar, que inclui uma reforma universitária em vista da industrialização do país, e o redirecionamento da comunidade dos cientistas sociais para a academia, que aliás teve seu início jána década de 1940, após a Reforma Capanema (de 1942), que logrou enfraquecer os debates acerca da modernização da sociedade brasileira por meio da educação. A invisibilidade da sociologia no ensino médio atualmente é contrastante com a produção sobre ensino de sociologia no secundário entre as décadas de 1930 e 1950. É que nestas a prática científica de nossos intelectuais estava "organicamente" ligada à escola e aos institutos de formação de professores. Se não temos uma visão ampla e clara sobre a prática profissional dos sociólogos no ensino médio isso se deve ao insulamento descrito e não a uma suposta natureza da ciência. De qualquer modo, o que importa - especialmente para o presente texto - é considerar a produção, de ontem e de hoje, voltada ao ensino da sociologia no secundário - ou ensino médio -, tanto quanto os textos de reflexão sobre ensino de sociologia como produções intelectuais relevantes que participaram - ou participam - do debate público, da construção de um projeto que se pretende modernizante da sociedade e do Estado brasileiro, com vistas à democratização das relações sociais e formação do indivíduo/ cidadão.

Ao que parece, a história das ciências sociais brasileiras, especialmente no ensino médio, é decantada no duplo sentido da palavra, separada de seus aspectos considerados residuais e celebrada em hino de louvor à ciência. Entre os aspectos residuais estariam suas possibilidades de inserção no ensino médio. Por outro lado, como sugere Villas Bôas (1998), se pretendemos compreender a insistência na inclusão da disciplina, mais que o fato dela nunca ter figurado de modo estável nos currículos escolares, cabe verificar as justificativas que vêm sendo elaboradas acerca da disciplina, como as interpretações do Brasil são por ela mobilizadas e quais as suas relações com os ideais educacionais construídos em momentos distintos da história brasileira. 


\section{A MISSÃO DE SER MODERNO: O DISCURSO EDUCACIONAL NOS PRIMEIROS MANUAIS E PAPERS SOBRE ENSINO DE SOCIOLOGIA}

Uma característica emerge com muita clareza do período dos primeiros manuais didáticos e textos de discussão sobre ensino de sociologia: o sentido de missão do intelectual, para produzir o conhecimento da realidade e apontar os rumos a serem trilhados. Essa perspectiva está presente na Primeira República, se aprofunda e ganha novos significados sob o impacto do processo vivenciado ao longo dos anos 20 e 30 . Mas não houve um "salto de paradigma" em relação à produção "enciclopédica". 0 que Meucci (2000) observou nos manuais didáticos das primeiras décadas do século XX foi justamente um descompasso, uma divergência clara entre a proposta dos autores dos manuais - que ia de encontro aos ideais modernizantes, de questionamento da tradição livresca e estabelecimento da sociologia como disciplina científica - e os próprios manuais, recheados de definições conceituais.

Entre as razões oferecidas para explicar a contradição está o fato de não haver dados estatísticos acerca de nossa vida social (MEUCCI, 2000). Em parte, pois levantamentos sistemáticos entre nós são realizados desde a segunda metade do século XIX, especialmente a partir de 1871, com a criação da Diretoria Geral de Estatística, ainda que os censos e levantamentos realizados não tenham sido totalmente bem sucedidos até 1907 devido à dispersão de métodos e medidas através das províncias, estados e municípios (BOMENY, 2001). Mas a existência de dados estatí́sticos não garante, nem pode garantir, uma orientação diferente ao texto dos livros didáticos. E o fato de manuais apresentarem dados empíricos não faz deles livros menos tradicionais.

Outra razão bem mais óbvia e direta seria a própria formação dos autores dos manuais - que se deu principalmente nas faculdades de direito, uma formação erudita e bacharelesca, portanto, em desacordo com os padrões de pesquisa dos grandes centros científicos da Europa e dos EUA; no entanto, esta explicação não me parece suficiente se dita desta forma. Creio que a questão da formação do professor/ autor de manual é algo que estranhamente têm sido secundarizado como fator de condicionamento, porém não se resume à sua origem escolar. A formação dos autores desses primeiros manuais é manifestação de um "caldo de cultura" comum, está relacionada a um contexto mais amplo que somente pode ser bem compreendido se considerarmos os ideais mobilizados no período frente à crise da Primeira República e às mudanças estruturais no Brasil.

Propunha-se um ensino diferente, escreviam-se manuais não tão diferentes 
assim. E isso porque se sabia melhor do que não se aceitava mais na ordem estabelecida - institucional, intelectual, artística - do que o que se esperava em substituição a ela. Algo que curiosamente vemos se repetir atualmente no campo da educação e nos manuais produzidos a partir da década de 1980 (SARANDY, 2004). 0 descompasso entre objetivos propostos para a disciplina e o que os livros ofereciam de fato deve-se ao fato do movimento intelectual do período não ter acompanhado no mesmo grau, com o mesmo envolvimento e ritmo e igual produção de sentidos a emergência do modernismo ou, ao menos, da utopia modernizante no Brasil. Tomando por empréstimo a expressão de Milton Lahuerta (1997), o que havia no campo da reforma das instituições era uma postura "genericamente modernista". Ora, um problema que se impõe aqui é exatamente compreender o significado, ao nível discursivo, do modernismo dos sociólogos da época e seu efeito utópico ou conservador sobre a realidade institucional.

Todo o movimento intelectual do período se deu de modo bastante difuso, repleto de ambigüidades e contradições. 0 período foi marcado, portanto, pela insatisfação com os modelos vigentes e pela apropriação das novidades "modernas" européias e norte-americanas, que foram resignificadas e atualizadas no Brasil de acordo com a tradição vigente. Ora, foi a tradição discursiva na qual se formaram nossos intelectuais que permitiu a ordenação - nem sempre coerente, é verdade, mas significativa -, das experiências e idéias que manipulavam, num mesmo contexto de desilusão com a República e constatação do atraso resultante do modelo colonial ${ }^{7}$.

A utopia de modernização pela ciência e pela educação se manteve, apesar de tudo, como a "chave-mágica" que resolvia todas as contradições no plano do discurso, que funcionava "como dispositivo prático, que faz girar os empreendimentos e as aberturas, alternâncias de males do passado e benesses do futuro" (LAHUERTA, 1997), discurso que, se não emergia da prática concreta de indivíduos e instituições, tornava compreensível a direção a seguir. É nesse sentido que 0 passado é sempre condenado e lastimado, enquanto o futuro ansiado e louvado ${ }^{8}$. Apesar desse mesmo discurso modernizante poder ser compreendido também como ideologia própria à nossa "revolução passiva" (VIANNA, 1996), pois que almejava a modernização da sociedade brasileira pela educação, mas servia, em flagrante paradoxo, a uma educação elitista.

\footnotetext{
${ }^{7} 0$ que permite compreender o fato de Achiles Archero, em seu manual Lições de Sociologia, de 1935, discorrer sobre 23 definições de sociologia ao mesmo tempo em que se alinhava ao objetivo de incitar os estudantes à pesquisa empírica (MEUCCI, 2000, p. 39-40).

${ }^{8} 0$ desejo de ser moderno se transfigurou em verdadeira cruzada missionária, com a educação à frente, especialmente ancorada em noções como "civismo" e "civilidade" (MEUCCI, 2000).
} 


\section{UMA CIÊNCIA EMPENHADA: EDUCAÇÃO COMO ESTRATÉGIA DE SUPERAÇÃO DO ATRASO}

Os primeiros textos de reflexão sobre ensino de sociologia, bem como os primeiros manuais da disciplina, não apenas descreviam as teorias sociológicas que iam se desenhando na Europa e nos EUA - nem mesmo serviam unicamente à intenção de divulgação das idéias sociológicas -, porém faziam parte da produção de nossos intelectuais, além de contribuir para a legitimação de um novo campo de saber. Além disso, essas produções mantêm em comum o interesse em "nacionalizar" os conhecimentos sociológicos (e outros), como se pode perceber na intensidade das produções e publicações das décadas de 1920 e 1930 (MEUCCI, 2000). Mesmo antes, na primeira década do século XX nossos intelectuais já se mobilizavam para o conhecimento da realidade nacional a partir da elaboração de manuais didáticos de geografia e de "romances de formação" (BOTELHO, 2002), décadas de verdadeira efervescência intelectual, de um clima vertiginoso e uma ânsia por mudanças que somente se enfraqueceu e esfriou durante o Estado Novo e nos anos que se seguiram a ele.

Os manuais cumpriam várias funções. Entre outras: sistematizar - e traduzir - o conhecimento sociológico produzido na Europa e EUA; nacionalizar as ciências conforme o projeto de, a um só tempo, conhecer o Brasil e formar a nação; estabelecer um projeto de reforma das instituições, especialmente da educação, pela consolidação de uma consciência científica acerca da realidade social e política; por fim, levantar e divulgar dados, especialmente de caráter estatístico, acerca da realidade da época, algo de que muitos autores se ressentiram e declararam em prefácios (MEUCCI, 2000).

Se levarmos em conta todas as obras "de âmbito sociológico", ou assim consideradas, destinadas ao ensino, secundário ou superior, e publicadas num período que vai de algo em torno de 1899 - A propósito da teoria de Dürkheim, de Paulo Egydio, obra dirigida aos bacharéis de direito - até, pelo menos, 1935 - data da famosa obra Princípios de Sociologia, de Fernando de Azevedo, e num momento em que já havia a disciplina nos cursos normais, em São Paulo, Rio de Janeiro e Pernambuco, tanto como já funcionavam cursos de Ciências Sociais na Escola Livre de Sociologia e Política, na Universidade de São Paulo e na Universidade do Distrito Federal, e Caio Prado Jr., Gilberto Freyre e Sérgio Buarque de Holanda já tinham publicado suas célebres obras - constataremos que a produção de textos denominados didáticos teve o sentido, na época, de produção teórica autônoma por parte de nossos intelectuais e atendeu a um projeto distinto, tanto quanto expressava os conflitos entre grupos intelectuais e políticos. 
Em outros termos, discutir o ensino da disciplina - ou produzir obras voltadas a ele - era, antes de mais nada, se apropriar desse campo científico e firmar-se enquanto intelectual no debate público sobre a realidade brasileira.

Os manuais de então não representavam produtos com fins estritamente pedagógicos - muito menos comerciais. Os fins eram pedagógicos, sem dúvida, mas tratava-se de educar o povo brasileiro e, em especial, sua elite dirigente. Seus autores não constavam entre professores desconhecidos dos círculos intelectuais; nem todos lograram produzir obras que viriam a ser tornar clássicas e chegar aos nossos dias como ainda relevantes (ao menos para a historiografia da disciplina), no entanto, estavam entre os mais respeitados nomes da inteligência brasileira. Ora, não podemos crer que seus escritos tenham ficado restritos somente às salas de aula, tanto como se pode supor razoavelmente que suas intenções iam além de uma contribuição aos professores da disciplina. Suas obras foram, sem dúvida, obras de sistematização teórica, tanto quanto de produção de conhecimento sobre o Brasil - como se afirmavam nos próprios manuais, era preciso, na visão de seus autores, dar início a uma "sociologia brasileira" -, tanto quanto foram textos empenhados nos debates políticos e culturais da época.

E se ainda considerarmos as (possivelmente mais de) três dezenas de livros publicados, dentre os manuais do secundário somente, num período de profundas e rápidas transformaç̧ões da sociedade brasileira em direção à urbanização, industrialização e re-ordenamento de suas forças políticas, com profundas implicações na configuração e dinâmica do Estado, concluiremos que elas constituíram um esforço de ordenamento da própria realidade brasileira. Caberia perguntar por que tantos intelectuais de projeção se dedicaram à produção dos manuais didáticos. Contribuir para o desenvolvimento educacional no país? Nacionalizar conhecimentos ao invés de simplesmente traduzir manuais estrangeiros - com os quais certamente estavam familiarizados? Participar dos debates da época - admitindo-se que os manuais eram mais que manuais? A resposta, provavelmente, estará em todas as assertivas por trás das perguntas levantadas, tanto quanto se deve considerar que, à época, escrever um manual, de certo modo, ése apropriar do conhecimento de um dado saber para a qual não se obteve formaç̧ão acadêmica nos padrões de uma tradição disciplinar universitária.

0 projeto era a remodelação do Brasil e, para isso, se acreditava na promessa da ciência como orientadora fiel e na educação como estratégia. Os conflitos envolviam grupos ligados à Igreja, movimento operário, os integralistas, setores tradicionalistas ligados à oligarquia dominante, militares, setores da burguesia industrial, profissionais liberais e assim por diante; em relação aos autores dos manuais didáticos, esses conflitos se localizaram principalmente entre o grupo dos intelectuais católicos e os que se 
alinhavam a uma concepção laica de educaçã̃o ${ }^{9}$; ou se distribuíam em diversos embates entre os defensores de uma formação bacharelesca e cunhada nas humanidades e letrase aqueles que viam na formação científica a adequação do homem às transformações do tempo presente. Que grupos eram esses? Que interesses almejavam e quais os jogos de poder desenharam em torno do controle sobre campo tão disputado como foi à educcção? Nesse ponto, abre-se interessante campo de pesquisas.

A conclusão lógica desse quadro é a constatação da importância que davam os intelectuais da época à educação, com eles os primeiros sociólogos; mas não somente à educação de um modo abstrato e geral: dotavam de grande relevância as questões práticas de ensino da sociologia. É na articulação entre educação, ciência - com a sociologia à frente - e democracia que encontrará o sentido do projeto político dos intelectuais do período. Segue a isso, ainda, a produção não apenas de obras didáticas, mas de textos sobre o ensino de sociologia no secundário ou de ciências sociais de um modo geral, sendo muito comum, por exemplo, nesses manuais, a inclusão de capítulos, seções ou prefácios com reflexões a esse respeito, a exemplo da obra Teoria e Pesquisa em sociologia, de Donald Pierson, em que inclui um capítulo com o título Estudo e Ensino da Sociologia.

É bastante significativo o fato - pouco evidenciado pelos próprios sociólogos - de que a primeira revista especializada, Sociologia, editada e dirigida por Romano Barreto e Emílio Willems, tivesse como título "Sociologia: revista didática e científica", e cujo primeiro número, de 1939, trazia no editorial o objetivo da revisa: auxiliar o estudante, dar subsídios aos professores da área e lançar os fundamentos de uma sociologia brasileira. A ciência social das décadas dos primeiros manuais foi uma ciência empenhada. Havia um projeto, portanto, que ainda aguarda explicação - interpretações acerca do atraso brasileiro e utopias modernizantes que ainda hoje requerem esforço investigativo -, especialmente no que tange ao lugar que a sociologia ocupava no ideário dos intelectuais da época. Um projeto científico e prático, porque de intervenção por meio da educação.

\footnotetext{
${ }^{9}$ Como Meucci (2000, p. 45-100) bem demonstrou, os manuais também expressam as lutas ideológicas e políticas, os embates entre movimentos intelectuais e as esperanças de um determinado tempo, daí a distinção que faz entre os manuais escritos por sociólogos - como os de Achiles Archero Júnior, Lições de Sociologia (1932), e Fernando de Azevedo, Princípios de Sociologia (1935) -, e os escritos por intelectuais ligados à Igreja, como os de Alceu Amoroso Lima, Preparação à Sociologia (1931), e Francisca Peeters, Noções de Sociologia (1935). A principal diferença entre os dois grupos está em que, para os primeiros, a sociologia foi concebida enquanto disciplina científica destinada a contribuir para o desenvolvimento da moderna sociedade brasileira - justamente por possibilitar a capacitação dos indivíduos para o enfrentamento das mudanças do mundo tecnológico a partir da apreensão dos procedimentos e métodos de investigação científica e do estabelecimento de padrões de civilidade e civismo entre os alunos; enquanto que, para os sociólogos católicos, a sociologia se constituía antes como uma "disciplina moral", ao lado da Ética e do Direito, cuja finalidade principal seria a afirmação dos dogmas e dos valores cristãos, um tipo de apostolado bem exemplificado pela obra de Amoroso Lima. Esse embate se deu, fundamentalmente, em torno da questão da manutenção ou retirada do ensino religioso obrigatório.
} 


\section{SOCIÓlOGOS-EDUCADORES, EDUCADORES-SOCIÓLOGOS}

Segundo Bomeny (2001, p. 28), Miguel Couto já dizia que "no Brasil, só há um problema nacional: a educação do povo". Miguel Couto, era médico, participou ativamente das campanhas de reformas nacionais e foi o primeiro ministro da saúde no Brasil, em 1953. Participou também da desilusão ante as promessas não cumpridas da República que fez com que se elegesse a educação como a solução dos problemas do país (CARVALHO, 1997, p. 115). Há verdadeiramente, durante as primeiras décadas do século XX, um "entusiasmo pela educação" como a panacéia dos problemas da sociedade brasileira. Mas esse argumento não explica totalmente 0 investimento na educação por parte da inteligência brasileira. A ele deve-se ligar outros fatores se desejarmos um quadro mais completo.

A utopia da moderna sociedade do trabalho foi sendo construída nos debates empreendidos no Brasil a partir da constatação de um "mal-estar" que, se tem origem numa "consciência do atraso" que vai se formando desde a campanha abolicionista (ao menos), assume contornos nítidos com a crise enfrentada pelo pensamento liberal durante a Primeira República. A percepção do atraso da sociedade brasileira foi relacionada, num primeiro momento, ao debate sobre as raças, sobre a formação do "povo brasileiro", sobre questões referentes à alimentação e à saúde, tanto quanto sobre os problemas de organização e funcionamento do Estado. Com a República, tratava-se de constituir a nação, e uma nação não se faz sem um caldo de cultura comum ou, em outras palavras, de um povo unido em torno de ideais compartilhados e de uma mesma moral. Daíjáse pode vislumbrar os caminhos que o pensamento vai tomar rumo à definição do papel da educação. Por outro lado, um tal projeto não se faz sem a participação ativa do Estado, e era preciso definir-lhe o modelo.

Mas o caso é que logo após os primeiros anos de vigência percebeu-se que a República não realizara as promessas acalentadas no incipiente sonho liberal brasileiro. Nesse momento, portanto, tratava-se de identificar as causas do problemae, a despeito da diversidade de diagnósticos, logo se tornou consenso uma desconfiança em relação à possibilidade de implantação das instituições liberais no Brasil - e à real necessidade do componente democrático na ordem burguesa brasileira. A isso estava associada à percepção do papel das elites tradicionais como obstrução do progresso - o que não incorre em negar preponderância às elites como condutoras do processo de construção nacional. Elite retrógrada e povo atrasado, esses os dois termos do diagnóstico empreendido pela "vanguarda" intelectual nacional. Por um lado, então, temos a idéia da necessidade de formação do povo e, por outro, de uma reforma das elites.

A crise da Primeira República e a constatação da precariedade da educação no 
Brasil do início do século motivou a criação das Ligas de Defesa Nacional e da Associação Brasileira de Educação em 1924, que abrigou inúmeros debates sobre modelos vigentes na Europa e nos EUA, de onde retiraram inspiração os construtores de políticas públicas voltadas à educação no Brasil. Aesse desgosto com os rumos que havia tomado a República, portanto, se juntava uma insatisfação crescente com a atmosfera intelectual presente: "excesso de formalismo nos estilos literários", "formação humanista ornamental", "descompasso com a produção dos centros mais avançados", "aprisionamento da expressão - artística e intelectual - em fórmulas arcaicas", "desconhecimento do Brasil e do brasileiro" eram opiniões crescentes no seio da inteligência nacional. Trata-se, portanto, de realizar uma ampla reforma das idéias, especialmente da formação superior das elites, das manifestações artísticas e literárias; transformações que deveriam ser conduzidas pelo Estado, por inspiração dele, apesar dele ou contra ele, conforme os matizes que se desenharam. Mais uma vez, tudo concorria para o entendimento da educação como alavanca do progresso.

E a filosofia positiva de Augusto Comte se apresentou como a bússola a orientar, no Brasil, os rumos que a educação deveria trilhar. Ela tem seu momento de consolidação enquanto doutrina e movimento organizado em 1876, quando se fundou a primeira sociedade positivista em nosso país, com a participação de Benjamin Constant. Sabe-se que desde 1850, pelo menos, há registros da influência da filosofia positiva no Brasil e que sua influência, mesmo não tendo sido tão decisiva no processo que conduziu à República como já se acreditou, ficou para sempre marcada no dístico da bandeira nacional, "ordem e progresso". Mas é fato que os positivistas jogaram algum papel nas reformas educacionais do Brasil. Não édifícil compreender: do ponto de vista filosófico o positivismo propugna uma reforma intelectual e moral dos homens como condição primeira para a reforma das instituições e uma classificação das ciências. Como ciência superior, justamente a última a ser desenvolvida, pois implicava a evolução do espírito humano, a sociologia figurava como aquela capaz de, reformadas as consciências, determinar cientificamente as condições, princípios e métodos da reforma prática da sociedade. Ora, se do ponto de vista de suas idéias, todo o projeto de Augusto Comte é um projeto educacional, do ponto de vista das associações históricas e atualizações de seu pensamento promovidas pelos intelectuais brasileiros, após a proclamação da República e da abolição do trabalho escravo, restava preparar o homem brasileiro para o estágio científico que se seguiria. Se não se podia aceitar mais o Império, também não se podia acreditar numa sociedade de sábios onde a quase totalidade da população não era alfabetizada. 
Já se observou que, na prática, os positivistas brasileiros inverteram o preceito comtiano da reforma moral, antes de uma reforma institucional (MORAES, 1997). De fato, ainda que almejando uma ampla campanha educativa nacional, nossos militantes positivistas previram no Estado, em especial nas suas instituições militares, o meio estratégico para a consecução de seus fins. Tratava-se, portanto, de reformar as instituições para educar, de estabelecer a ordem que nos levaria ao progresso dentro dessa ordem. Fato que nos impõe nítidos limites quanto à explicação da opção pela educação feita pelos intelectuais da Primeira República: obviamente, nem todos eram positivistas; e as idéias positivistas, tendo sido atualizadas no país, pressupõem outros fatores de afinidade eletiva com os ideais da educação e da modernização, tal qual foram construídos nacionalmente.

Nossos primeiros sociólogos sofreram forte influência positivista através do pensamento de Dürkheim, mas não somente dele. Os sistemas filosóficos e científicos amplamente adotados nas faculdades de direito - de Recife e de São Paulo - e a crescente influência da propaganda do positivismo enquanto movimento mais ou menos organizado, especialmente forte nos círculos militares, estabeleceu algo como um paradigma ou um padrão filosófico e científico com autoridade perante as produções intelectuais da época que tornam compreensível a eleição da educação como instrumento privilegiado para alcançarmos nossa modernidade. Havia um modelo discursivo hegemônico e uma agenda definida.

Numa fórmula bem próxima do ideário positivista, saúde, moral e trabalho constituiriam os pilares sobre os quais se construiria uma nação saudável e moderna. Tal era o trinômio sobre o qual se deveria assentar a educação popular. Um povo desnutrido, despreparado para o trabalho - pior que isso, um povo que não desenvolveu o ethos do trabalho, doente, portanto - do corpo e da alma -, de modo algum poderia constituir a nação a que o Brasil se destinava tornar-se. Era preciso tratar o povo - representado na figura do Jeca Tatu, de Monteiro Lobato -, extirpar-lhe a preguiça, a languidez com que se acreditava ele se movia. Era preciso fornecer-lhe uma moral afim as das civilizações modernas. Esse era um projeto que somente se tornaria possível pela educação e não se poderia realizá-la senão pela orientação da ciência. Porém, quem realizava o diagnóstico, o prognóstico e a cura eram as elites "modernas", que naturalmente não se reconheciam no quadro acima.

Daí a relação surpreendente entre esferas aparentemente tão díspares quanto a moral, a saúde e a educação. Mas no contexto da época fazia bastante sentido que, por exemplo, tenha sido criado o Ministério da Educação e Saúde em 1930, como uma só pasta. "Vitalizar pela educação e pela higiene toda essa gente reduzida pela vermina a meio-homem, a um terço de homem, a um quarto de homem" era a proposição de 
Miguel Couto já em 1927. E de modo algum se tratava de um projeto individual, basta observarmos as campanhas em torno da higiene e da saúde pública - autoritárias e impostas pelo Estado, a despeito de qualquer mérito. 0 povo era tido por uma "massa inculta", na expressão comum, mas como massa, moldável. E inculto e doente porque mestiço e despreparado para a vida democrática. Era ao Estado que se exigia, afinal, a tarefa de moldar o povo para construir a nação.

A educação, entendida como atividade ou projeto, não possuía os recursos necessários que a situação exigia. Daí ser o entendimento comum da época que apenas pela ciência seria possível "higienizar" a sociedade, não somente por um trabalho de saneamento, mas pela prevenção e tratamento das doenças endêmicas, inclusive morais. Higienização pela medicina, prevenção pela educação, conforme sugere Bomeny (2001). E esse apelo à ciência era compartilhado tanto por positivistas (de todos os matizes, inclusive os integralistas), quanto por católicos ou pelos educadores novos (sob influência do pragmatismo, apesar de também não constituírem um grupo homogêneo). Moralizar teria sentido amplo: criar a disposição e o preparo para o trabalho, preparo inclusive intelectual - porém até o necessário - e higienizar o indivíduo. Era preciso, pois, forjar o corpo e a mente do cidadão brasileiro, civilizá-lo. 0 fim último era operar a transformação do "Jeca Tatu" em cidadão, categoria que por si mesma abarcava a de trabalhador, ou era sinônima desta. E somente o trabalho poderia levar o Brasil à condição de nação industrializada e desenvolvida.

E se "saúde, moral e educação" havia se tornado a frente de batalha de nossos intelectuais do período, "modernidade, trabalho e utopia" foi o eixo comum que permitenos compreender o sentido percorrido pelos diversos movimentos que surgiram, no campo da educação ou fora dele. Se nos detivermos sobre os movimentos educacionais poderemos ir além ao observarmos que este mesmo eixo temático permanece significativo para a compreensão de um amplo período da história da educação brasileira, como sugere Ghiraldelli Jr (1994). Para ele, todos os movimentos educacionais no Brasil elaboraram "projetos no sentido de integrar o país na modernidade; esta, por sua vez [...] deveria realizar a utopia nacional de desenvolvimento e de justiça social. Tal utopia da modernização teria, como um dos motores propulsores e como um dos pontos de chegada, a educação ligada ao trabalho ou pensada a partir dele" (p. 149-150).

É razoável pensarmos que o impacto do "clima" daépoca não se fez sentir somente nas letras, porém o foi igualmente em todos os círculos intelectuais do país: neste sentido, e descontando os exageros prováveis, tivemos um modernismo na literatura tanto quanto nas ciências e no imaginário social e político brasileiro. 0 nosso recurso à ciência também advém das influências da filosofia pragmática, especialmente de Dewey. Como se sabe, 0 
Manifesto dos Pioneiros da Educação Nova, de 1932, redigido por Fernando de Azevedo (um durkheimiano, recordemos), recontextualiza o pensamento educacional norteamericano. E também aqui a educação será articulada num projeto de construção da nação, de uma modernização pela ciência, que, por sua vez, somente poderia ser efetivada pela reforma da educação.

Em síntese, poderíamos afirmar que a ciência social do pós-30 compreendeu o pensamento social e político anterior como enciclopédico e o caracterizou como a fase pré-científica da disciplina - o que relegou sua produção a algo de menor importância em comparação com o novo período, da pesquisa científica moderna; ainda assim - e no afã de revelar a relevância, urgência mesmo, do conhecimento sociológico -, os cientistas sociais da época se debruçaram sobre a questão da educação - e do próprio ensino de sua disciplina -, algo posteriormente abandonado quando da realização da meta mais ambicionada, a consolidação do campo na academia e seu reconhecimento enquanto ciência instituída nos modernos quadros da divisão disciplinar. Agora, é a época de Florestan Fernandes que é relegada a uma fase pré-científica, tida por refém dos debates internos acerca de sua organização disciplinar e ensino, por vezes denunciada como produtora de ensaios mais que de pesquisas empíricas, ainda muito afastada da pesquisa considerada substantiva ${ }^{10}$.

Positivismo, Modernismo, Pragmatismo. A partir deste trinômio é possivel compreendermos a atuação de nossos primeiros sociólogos e o fenômeno tratado neste texto, qual seja, o interesse deles pela educação e, especificamente, pelas questões do ensino da disciplina. Tanto quanto é possível compreendermos na medida justa os manuais produzidos nas primeiras décadas do século XX. Eles constituem o tripé do cenário intelectual na primeira metade do séc. XX. Podemos, então, afirmar que se a inteligência nacional dos anos 20 elegeu como questões de sua preocupação imediata a "saúde, a moral e a educação", e tinha, como eixo temático comum, "a modernidade, a utopia e o trabalho", suas influências predominantes, do ponto de vista de seu ideário e dos meios de intervenção mais eficazes, foram esses três grandes movimentos intelectuais que se articularam na elaboração do imaginário social brasileiro na passagem do século XIX ao XX.

\footnotetext{
${ }^{10}$ Uma nova possibilidade de pesquisa se abre com o discurso educacional das últimas três décadas, em que novos paradigmas permearam as disputas internas ao campo pedagógico e sociológico e durante o qual uma certa "pedagogia marxista" vem conflitando com (e perdendo espaço para) o paradigma flexibilizador da educação orientada por "competências e habilidades" (novamente, com forte influência de Piaget, mas também do pragmatismo). Eé exatamente aqui que o ensino de sociologia merece destaque na pesquisa, como recorte específico do discurso educacional analisado. Se na primeira metade do século XX ocupava lugar de destaque nos debates educacionais e políticos, atualmente é relevado à periferia acadêmica, tratado com indiferença pelos gestores públicos da educação e abandonado ao discurso corporativista dos "sindicatos de sociólogos".
} 


\section{De “arte de SALVAR RAPIDAMENTE o Brasil” A UMA “NOTA DE RODAPÉ"}

Apesar da indiferença com que vem sendo tratado o ensino de sociologia no ensino médio pela comunidade dos cientistas sociais, refletir sobre a sociologia enquanto disciplina no secundário ou no ensino médio é refletir sobre as ciências - e as ciências sociais em particular -, no Brasil. A história da sociologia no ensino médio se confunde com a história da constituição do campo das ciências sociais no Brasil (MEUCCI, 2000) tanto quanto com a organização de nosso sistema educacional; a disciplina fez-se presente no debate público desde o Império, foi alçada à condição estratégica de modernização democrática da sociedade brasileira, para, por fim, tornar-se questão presente naquilo que Nietzsche chamou de "história de antiquário", ou uma simples "nota de rodapé" Giglio (1999) em papers acadêmicos ou pior, ponto programático dos discursos corporativistas dos "sindicatos de sociólogos".

Uma espécie de culto à ciência - e o sentido de missão da ciência, e das ciências sociais em particular -, desaguou em análises sociais que justificavam o papel preponderante da sociologia no quadro da produção intelectual brasileira, como em Costa Pinto e Florestan Fernandes, para os quais

o mundo em que se vivia estava perdido pela lógica da modernização e da secularização, extremamente racionalizado e burocratizado, no qual a ciência ocuparia progressivamente todas as ações dos indivíduos e, por isso, todos deveriam render-se inevitavelmente a ela - até mesmo como garantia ao êxito de suas ações. Portanto, caberia intervir em uma sociedade como a brasileira para, no momento de modernização e de instalação da nova ordem social, buscar meios de liberar 0 indivíduo do atraso e da antiga ordem que atravancaria 0 acesso deste à democracia e à estrutura social capitalista (GIGLIO, 1999, p. 80).

Diante desse diagnóstico,

seria necessário criar o espaço para uma intelligentzia que, como estrato distinto pelo seu vínculo com a ciência, exerceria um mandato público de intérprete da realidade que iluminaria o caminho da sociedade através de planejamento e controle. Logo, ao mesmo tempo em que Florestan Fernandes e Costa Pinto estão afirmando o significado da ciência como expressão máxima da racionalidade que vem operando e deve impregnar a organização moderna, eles também estão fazendo a defesa e consolidação das ciências sociais em geral e da sociologia em particular (GIGLIO, 1999, p. 80). 
A sociologia participaria do jogo político como o "símbolo máximo da racionalidade" crescente do mundo moderno e da ruptura da sociedade brasileira com 0 seu passado, e seu ensino, inclusive nas escolas do secundário, o instrumento para "elevar o nível intelectual das grandes massas", segundo Florestan (1975), e como instrumento de mudança social num contexto de democratização, pois produziria respostas aos problemas sociais vigentes, tanto quanto novas técnicas de controle social.

0 debate empreendido por Florestan Fernandes e Costa Pinto acerca do ensino de sociologia no ensino secundário se inscreveu num objetivo teórico-político muito maior, qual seja, o da reforma social e da democratização da sociedade brasileira tendo, como fundamento, o papel do conhecimento científico, e em especial o da sociologia, enquanto instrumentos adequados para a capacitação dos indivíduos no sentido da intervenção na realidade diante da secularização das sociedades modernas ${ }^{11}$.

Para os intelectuais que estavam diretamente sob a influência das idéias de Dewey - como Anísio Teixeira e Monteiro Lobato, posteriormente, com menor impacto e várias reelaborações, Fernando de Azevedo - representava a possibilidade de reformar-se a sociedade, capacitando os indivíduos perante as transformações modernizantes do processo de industrialização e urbanização (COSTAPINTO, 1947), a educação comportava uma intenção interventora sobre a realidade pela mobilização da pesquisa empírica, um fim determinado, a constituição de uma nação moderna formada por indivíduos adaptados à vida democrática e competentes para enfrentarem as mudanças que se apresentavam com a intensa industrialização, e um meio para se realizar esse projeto de modo eficaz, a apropriação do conhecimento científico por ampla parcela da população brasileira (CUNHA; TOTTI, 2004). Não se pode negar aqui a aproximação entre esses sociólogos e a Educação Nova no Brasil. Isto porque o pragmatismo, na acepção deweyana, influência possível sobre os "sociólogoseducadores" ou "educadores-sociólogos" do período em que escrevem Florestan Fernandese Costa Pinto, propõe que "a capacidade para empreender a reconstrução de ideais em um quadro de referência social é o resultado de programas educacionais e o ingrediente indispensável de uma democracia bem-sucedida" (LEVINE, 1997, p. 233).

\footnotetext{
${ }^{11}$ São objetivos do ensino de sociologia, segundo Costa Pinto: "1) dar conhecimentos positivos e estabelecer conceitos fundamentais sobre a vida social, suas bases, sua organização, seus processos e seus produtos; 2) tomar essas informações e conhecimentos científicos sobre a vida social como pontos de partida e como materiais para gerar e elaborar no educando atitudes, estados de espírito e formas de comportamento capazes de dar caráter ativo e consciente à sua participação e integração na sociedade e na cultura" (COSTA PINTO, 1947, p. 15, grifos meus). É curioso o fato de Luiz de Aguiar Costa Pinto, em sua Tese de Livre Docência, já referida neste trabalho, fazer largo uso de uma terminologia bem próxima da dos Pioneiros da Educação Nova e da ciência entendida como método, numa noção não muito distante do positivismo. Esta questão merece estudo mais aprofundado: até que ponto se pode reconhecer uma predominância do pragmatismo deweyano, do positivismo ou da sociologia de Dürkheim nos escritos dos sociólogos da época?
} 
Ao que parece, o projeto previsto para a disciplina atendia, ainda, ao objetivo de estabelecimento de uma identidade nacional - sempre, no Brasil, ligada a intervenções no sistema educacional, conforme a literatura especializada sobre história da educação (GIRALDELLIJR., 1990; PAGNI, 2000; BOMENY, 2001; MEUCCI, 2000; CARVALHO, 1997) -, isto é, o projeto de criação da Nação Brasileira passava pelo projeto de criação de uma Identidade Nacional, que implicava um projeto educacional de ajustamentos culturais de vastos segmentos da população brasileira. Exemplo disso é a "constatação" de Anísio Teixeira quando afirma que "a verdade é que estamos cada vez mais longe da formação do cidadão indispensável ao difícil funcionamento da democracia liberal", um lamento que sintetiza bem a o projeto modernizante da educação (TEIXEIRA, 1969 apud PAGNI, 2000).

Articulou-se, no período, educação, ciência e democracia de modo singular; visão que se aliava ao impulso modernista que encontrava na formação enciclopédica das elites uma das causas da crise da República Velha e que projetava no futuro os anseios de modernização democrática da sociedade brasileira em intenso processo de industrialização. É com esse espírito que Fernandes e Costa Pinto propõem o retorno da sociologia para 0 currículo do antigo secundário, para os quais uma das tarefas da escola é dar aos jovens elementos intelectuais de uma "cidadania consciente" (COSTAPINTO, 1947 apud GIGLIO, 1999, p. 58). Isso porque "a ciência operava num mundo que se transformava para 0 moderno e a sociologia ensinaria ao indivíduo a 'como pensar' as situações sociais complexas que o rodeiam com um método rigorosamente científico"” (COSTA PINTO, 1947, p. 62-63). Ora, "a ciência seria portadora de civismo" e considerando-se o papel da educação na sociedade moderna, a sociologia ocuparia posição privilegiada, influindo em sua dimensão política na construção da perspectiva democrática” (GIGLIO, 1999, p. 77-78). Mas, para tanto, haveria uma opção pela sala de aula como o espaço do "fazer ciência", não pela "ciência feita", segundo proposta de Fernando de Azevedo (SANTOS, 2002, p. 108) $)^{12}$

Para os "novos educadores", a ciência contribuiria não apenas como disciplina a ser ensinada nas escolas - o que certamente estava previsto dado o caráter civilizacional da ciência -, porém para a própria determinação das finalidades educacionais, dos melhores métodos de ensino e até mesmo da organização administrativa mais adequada

\footnotetext{
${ }^{12}$ A referência de Fernando de Azevedo é de Princípios de Sociologia: pequena introdução ao estudo de Sociologia geral. São Paulo, Duas Cidades, 1973. introdução, p. 7. A crítica ao ensino da "ciência feita", por Fernando de Azevedo, pretendia atingir, principalmente, a educação "enciclopédica" e marcar uma diferença fundamental quanto à sociologia no ensino secundário, que deveria privilegiar a aprendizagem, por parte dos alunos, dos métodos e modos de pensar da investigação científica. Essa crítica de Azevedo também foi recuperada por Meucci (2000).
} 
da escola. À época de Costa Pinto o sentimento da urgência de um pensamento sobre as questões de ensino era patente; pensar o Brasil e pensar a escola, a educação e o ensino da própria disciplina era uma só e mesma atividade intelectual, de valor idêntico. Tratavase, em estreita afinidade com o movimento escolanovista, do estabelecimento de "um programa que só seria plenamente efetivado no futuro, quando fosse inteiramente ultrapassada nossa tradição intelectual enciclopédica" (CUNHA; TOTTI, 2004, p. 4).

Porém, já naquele momento iniciava-se o insulamento das ciências sociais em âmbito acadêmico e, contraditoriamente, seu distanciamento das questões de ensino. A reforma do sistema universitário brasileiro a partir da década de 1930 foi realizada com base no sistema francês e em prol da necessidade de renovação das elites (Giglio, 1999, p. 28), dificultando a realização do projeto escolanovista de inspiração norte-americana, fato que possivelmente acabou contribuindo para um insulamento ainda maior dos cientistas sociais mais jovens e de seu proposital distanciamento do que vinha fazendo a geração anterior, a exemplo das palavras de Florestan Fernandes:

Postos diante das expectativas conservadoras dos 'donos do poder', eu e meus companheiros de geração não procuramos nos incorporar às elites culturais do país; apegamo-nos a um radicalismo científico, que servisse, ao mesmo tempo, como um escudo protetor e um recurso de auto-afirmação [...]. Procuramos legitimar uma área própria de autonomia intelectual e o fizemos em nome da 'ciência' e da 'solução racional' dos problemas sociais" (FERNANDES, 1977 apud CUNHA; TOTTI, 2004, p. 10).

Se 0 ideário renovador logrou conquistar a institucionalização da pesquisa e do desenvolvimento científico, sua vitória foi apenas parcial, dada a articulação que faz entre ciência, educação e democracia. Portanto, a perspectiva de Florestan Fernandes é denunciadora do gradual afastamento que as gerações de cientistas sociais foram estabelecendo em relação às antecessoras, com consequiências diretas para as reflexões sobre ensino de ciências sociais.

Segundo Melo (1999, p. 21-36), o intelectual tem sido visto de diversos modos, a ele se articulando diversos papéis. Sem desejar percorrer toda a argumentação do autor, basta lembrar que o intelectual pode ser visto ou como um "verdadeiro intérprete de seu tempo", ou pode ser compreendido como o cientista especializado e competente para "traduzir" aos leigos, portanto, para a esfera pública, as questões que se colocam no curso da história. Ora, o que está em questão para Florestan Fernandes e Costa Pinto - mas não somente para eles - é o papel relevante que o cientista social poderia e deveria assumir perante a realidade social, como cientista especializado e como "o intérprete da sociedade", de seus interesses e de seus conflitos. 
0 resgate desse debate talvez - e sua interpretação à luz do contexto em que emergiu - pudesse evitar o que o próprio Florestan Fernandes avaliou como uma perda ao se referir a uma espécie de "geração perdida", conforme escreve em artigo com esse título, relembrado por Giglio (1999, p. 9):

no fim de umas três décadas, o que pretendíamos fazer já não possui sentido prático e vemos os 'novos' retomar os mesmos caminhos, para refazer o que já foi feito, sem aproveitar o esforço de um avanço que, pelo menos, deveria representar um novo ponto de partida e uma reflexão crítica mais madura e profunda quanto às relações entre talento e sociedade no Brasil.

\section{REFERÊNCIAS}

AZEVEDO, Fernando de. A sociologia no Brasil: o ensino e as pesquisas sociológicas no Brasil. In: WILLEMS, E. Dicionário de sociologia. 4. ed. São Paulo: Globo, 1969.

BOMENY, Helena. Os intelectuais da educação. São Paulo: Jorge Zahar, 2001.

BOTELHO, André. Aprendizado do Brasil. a nação em busca dos seus portadores sociais. Campinas: Unicamp, 2002.

CÂNDIDO, Antônio. Literatura e Sociedade. 8. ed. São Paulo: T. A. Queiroz, 2000.

CARVALHO, Marta M. Chagas. Educação e política nos anos 20: a desilusão com a República e 0 entusiasmo pela educação. In: DE LORENZO, Helena Carvalho; COSTA, Wilma Peres da (Org.). A década de 20 e o Brasil moderno. São Paulo: Fundação Editora da UNESP, 1997.

CORREA, Lesi. Projeto de Extensão Universitária, Laboratório de Ensino de Sociologia. Londrina: Universidade Estadual de Londrina, 1999.

COSTA PINTO, Luiz de Aguiar. O ensino da sociologia na escola secundária. Tese (Concurso à Livre Docência) - Faculdade Nacional de Filosofia da Universidade do Brasil, Rio de Janeiro, 1947.

CUNHA, Marcus Vinícius da; TOTTI, Marcelo Augusto. Do "Manifesto dos Pioneiros" à "Sociologia Educacional": ciência social e democracia na educação brasileira. Rio de Janeiro: FGV, 2004. 
FERNANDES, Florestan. 0 ensino da Sociologia na escola secundária brasileira. In:

A Sociologia no Brasil. Petrópolis: Vozes, 1975. Originalmente publicado nos Anais do I Congresso Brasileiro de Sociologia, 21-27 de junho de 1954, em São Paulo.

GHIRALDELLI JR., Paulo. A pedagógica marxista brasileira e o "esgotamento das energias utópicas da sociedade do trabalho": um caso de não-enfrentamento. In: . Educação e Razão Histórica. São Paulo: Editora Cortez, 1994, pp. 149-190.

GIGLIO, Adriano. A sociologia na Escola Secundária: uma questão das Ciências no Brasil-anos 40 e 50. 1999. Dissertação (Mestrado) - IUPERJ, Rio de Janeiro.

LAHUERTA, Milton. Os intelectuais e os anos 20: moderno, modernista, modernização. In: DE LORENZO, Helena Carvalho; COSTA, Wilma Peres da (Org.). A década de 20 e o Brasil moderno. São Paulo: Fundação Editora da UNESP, 1997.

LEVINE, Donald N. Visões da tradição sociológica. Rio de Janeiro: Jorge Zahar Editor, 1997 [1ª edição de 1995], tradução de Álvaro Cabral.

MEKSENAS, Paulo. 0 Ensino da Sociologia na Escola Secundária. In.: Leituras E Imagens. Grupo de Pesquisa em Sociologia da Educação. Florianópolis: UFSC, UDESC, 1995. p. 67-79.

MELO, Manuel Palácios da Cunha e. Quem explica o Brasil. Juiz de Fora: Editora UFJF, 1999.

MEUCCI, Simone. A institucionalização da sociologia no Brasil: primeiros manuais e cursos. 2000. Dissertação (Mestrado) - UNICAMP, Campinas.

MORAES, Amaury Cesar. Licenciatura em ciências sociais e ensino de sociologia: entre 0 balanço e o relato. Tempo Social, São Paulo, abr. 2003.

MORAES, João Quartin de. 0 positivismo nos anos 20: entre a ordem e o progresso. In: DE LORENZ0, Helena Carvalho; COSTA, Wilma Peres da (Orgs.). A década de 20 e o Brasil moderno. São Paulo: UNESP, 1997.

NUNES, Edson. A gramática política do Brasil: clientelismo e insulamento burocrático. 2.ed. Rio de Janeiro: Jorge Zahar Editor, 1999.

PAGNI, Pedro Ângelo. Do "Manifesto de 1932" à construção de um saber pedagógico. Ensaiando um diálogo entre Fernando de Azevedo e Anísio Teixeira. Ijuí: UNIJUí, 2000.

RÊSES, Erlando da Silva. ...E com a palavra: os alunos. Estudo das representações sociais dos alunos da rede pública do Distrito Federal sobre a sociologia no ensino médio. 2004. Dissertação (Mestrado) - UNB, Brasília.

SANTOS, Mário Bispo dos. A Sociologia no Ensino Médio: o que pensam os professores da rede Pública do Distrito Federal. 2002. Dissertação (Mestrado). Universidade de Brasília, Brasil.

SARANDY, Flávio Marcos Silva. A Sociologia volta à escola: um estudo dos manuais de sociologia para o ensino médio no Brasil. 2004. Dissertação (Mestrado) - UFRJ, Rio de Janeiro. 
VIANNA, Luiz Werneck. Caminhos e Descaminhos da Revolução Passiva à Brasileira. Dados, Rio de Janeiro, v. 39, n. 3, 1996. Disponível em: http://www.scielo.br/scielo.php? script=sci_arttext\&pid=S0011-52581996000300004\&lng=pt\&nrm=iso. Acesso em: 25 fev. 2007.

VILLAS BÔAS, Gláucia (Org). A importância de dizer não e outros ensaios sobre a recepção da Sociologia em escolas cariocas. Rio de Janeiro: Núcleo de Pesquisas de Sociologia da Cultura, 1998. (Série Iniciação Científica, n. 8). 